\title{
A NEW IMPROVED FORM OF THE HILBERT INEQUALITY AND ITS APPLICATIONS
}

\author{
Xuemei Gao And Mingzhe GaO
}

Abstract. In this paper, it shows a new improved form of the Hilbert inequality by introducing a proper weight function $\Omega(\lambda, x)$ with a parameter $\lambda\left(\lambda>\frac{1}{2}\right)$. As applications, a new refinement of Widder's inequality and an extension of Hardy-Littlewood's inequality are given.

Mathematics subject classification (2010): 26D15.

Keywords and phrases: Hilbert inequality, parameter, Widder inequality, Hardy-Littlewood inequality.

\section{REFERENCES}

[1] Bicheng YAng, On Hilbert's integral inequality, J. Math. Anal. Appl., 220(1998): 778-785.

[2] I. BRentić, J. PeČARIĆ, Generalization of Inequalities of Hardy-Hilbert's type, Math. Inequal. Appl., 2(2004): 217-225.

[3] G. H. Hardy, J. E. Littlewood And G. Pólya, Inequalities, Cambridge University Press, Cambridge, UK, 2nd edition, 1952.

[4] Jianquan Liao, Bicheng YAng, On Hardy-type integral inequalities with the gamma function, J. Inequal. Appl., 2017(2017): 131.

[5] Leping He, Yin Li And Bicheng YANG, An extended Hilbert's integral inequality in the whole plane with parameters, J. Inequal. Appl., 2018(2018): 216.

[6] Lianxiang Wang, Dezhi Fang, Mathematical Handbook, People's Education Press, Beijing, 1979.

[7] LukKassen, Lars-Erik Persson and Stefan G. Samko, Some sharp inequalities for integral operators with homogeneous kernel, J. Inequal. Appl., 2016(2016): 114.

[8] Mario Krnić, Mingzhe Gao, Josip PeČarić and Xuemei Gao, On the Best Constant in Hilbert Inequality, Math. Inequal. Appl., 2(2005): 317-329.

[9] MingZhe GaO, On Hilbert's inequality and its applications, J. Math. Anal. Appl., 212(1997): 316323.

[10] MingZhe Gao, On the Hilbert Inequality, Z. Anal. Anwend., 4(1999): 1117-1122.

[11] Mingzhe Gao, TAn Li And L. Debnath, Some improvements on Hilbert's integral inequality, J. Math. Anal. Appl., 2(1999): 682-689.

[12] Mingzhe Gao and Hsu L. C., A Survey of Various Refinements And Generalizations of Hilbert's Inequalities, J. Math. Res. Exposition, 2(2005): 327-343.

[13] D. S. Mitrinović, J. PeČArić, A. M. FinK, Inequalities Involving Functions and Their Integrals and Derivatives, Kluwer Academic, Boston, 1991.

[14] I. SCHUR, Bernerkungen sur Theorie der beschrankten Billnearformen mit unendlich vielen Veranderlichen, J. Math., 140(1911): 1-28.

[15] O. V. WIDDER, An inequality related to Hilbert's inequalities, J. London Math. Soc., 4(1924): 194 198.

[16] YUming Jin, Table of Applied integrals, University of Science and Technology of China Press, Hefei, 2006. 